H., who had made the above diagnosis, and desired me to operate. She was a Swede, twenty-one years of age, and had been married six months. From the age of fourteen, she had molimina of menstruation, but there had never been any flow. These symptoms varied in intensity, and consisted of pain in the groins, feeling of th fulness, and weight in the lower abdomen, sometimes so severe as to render her unconscious for a time. Since her marriage there had been frequent attempts at intercourse, accompanied with pain on her part, and but little satisfaction on the part of her husband. Her general health appeared to be good.

Physical examination showed the external organs of generation well developed, with the exception that the hymen was imperforate, and the meatus urinarius was so much enlarged that it readily admitted the forefinger. It, however, occasioned no incontinence of urine; this latter I also considered a fault of development, rather than a dilatation from the unsuccessful attempts at coition. With one finger in the rectum and one in the bladder, an indistinctly-fluctuating tumor was found to nearly fill the pelvis. By recto-abdominal palpation, no evidence of a distention of the uterus or tubes could be established.

June 24th, 1885. 'The patient being etherized, and a more careful examination being made, mainly for the purpose of determining whether the tubes were distended, a free incision was made through the hymen, which was about $3-16$ of an inch in thickness, and forty ounces of thick, chocolate-colored fluid removed. The uterus and tubes were then found unaffected, and the vagina was thoroughly cleansed with a solution of corrosive sublimate, 1 to 2000 . This canal was tilled with iodoform gauze, and the patient put to bed.

Subsequently, the temperature was never but once above the normal, which was on the evening of the second day, when it scored $99.5^{\circ}$. The iodoform dressings were changed each second day, which not only insured the cleanliness of the vagina, but promoted the healing of its walls, which were much thickened and granular, bleeding easily, but also in their application and removal, insured against any closing again of the hymen. She returned home in two weeks, and from letters received both from Dr. Towne and her husband, I am assured of her health and happiness. She menstruated but once after the operation, becoming pregnant almost immediately.

By the kindness of the late Dr. J. B. S. Jackson, my attention was called, some years ago, to a most remarkable specimen in the Museum of the Medical Improvement Society, which was removed post-mortem, the case having been under his care, and seen by several of the most prominent surgeons of this city practising thirty years ago. Both the uterus and vagina were dilated in this case to such an extent, that the fundus of the uterus reached the umbilicus; the Fallopian tubes also were greatly distended, feeling like sausages on either side of the uterus. Although the condition was recognized by all, yet non-interference was advised, and the patient succumbed to her disease.

In the treatment of the class of cases under consideration, I am sure that it is essential to determine whether the tubes, as well as the uterus and vagina, are distended by the retained menstrual flux, for if so, it will not be safe to make a free incision and empty the uterus and vagina, for either septicæemia will occur from the tubes, or there will be great danger of their rupture occurring from the increased peristalsis of their walls, excited into action by the contracting uterus. If, then, such condition be present, it would be best first to remove the distended tubes by laparo: tomy, and then make the free incision through the hymen, and empty the uterus and vagina. If, however, the retention of the fluid does not extend to the tubes, the case may be treated simply by evacuating the vagina, or vagina and uterus, and keeping the walls clean and the opposing walls from uniting by adhesive inflammation.

\section{RECENT PROGRESS IN THE CARE OF THE} INSANE.

\author{
BY WALTER CHANNING, M.D.
}

\section{INSANE CRIMINALS.}

"The Connection between Crime and Insanity" 1 is the name of a new book by Sander and Richter, reviewed by Dr. Pelman, who remarks that it has been an accepted fact among physicians who care for the insane, that criminals, who become insane while undergoing sentence, are not fit subjects for insane institutions. Nevertheless, in prison they occasion great trouble, and cannot be prevented from outbreaks of insanity. Whatever plans have been proposed for their provision, the opinion has been pretty unanimous to keep them out of asylums.

Dr. Sander, in his book, takes the opposite ground, and says that, in his opinion, special institutions for the criminal insane are not necessary. Dr. Sander's field of labor is at the great asylum at Dalldorf, where the observations embodied in his book have been made, and they certainly demand serious consideration.

From outside observation of affairs at Dalldorf, Pelman thinks the opposite opinion from that of Dr. Sander would be formed. And this would be strengthened by the communication of Sommer, in 1884, which described the trouble that had arisen from bringing insane criminals together at Dalldorf, in consequence of which it had been necessary to obtain the services of two prison officials, who, to a certain extent, acted as overseers of the division devoted to the care of this class.

Dr. Richter, in the first part of Dr. Sander's book, gives a history of 190 criminals treated at Dalldorf from 1880-1883. The number among these who made attempts to escape is considerable, while not a few succeeded, and others misbehaved themselves. The impression made on Pelman by reading the report of these cases, is that they are not fit subjects for a lunatic asylum.

Sander found that 75 per cent. were in an insane condition when they were sentenced. In only thirtyeight cases were the patients' condition discovered at the time of trial, so that the chance of being unfairly sentenced was only one in three. Out of fifteen paralytics, four only were discovered to be such!

There were six times as many persons among the insane in the institutions of Berlin, who had undergone criminal prosecution, as among the generally healthy population of Prussia, which, Sander thinks, demonstrates the close connection between insunity and crime.

Only eight per cent. were more dangerous and troublesome than the ordinary insane, but the women are left out in this estimate.

1 Die Beziehungen zwischen Geistesstörung und Verbrechen. Von Dr. W. Sander and Dr. A. Richter, Berlin, 1856. Beaprochen von Dr.
Pelman. All. Zeitschrift f. Psychiatrie. 22tes. Band, 4tes Hoft. 
In the smaller institutions, Sander thinks one or two rooms fitted up more strongly than the others will be sufficient for the criminal insane. In the larger institutions, an annex, or a connected building, or ward especially arranged for this class, will be sufficient.

$\mathrm{Be}$ the form of arrangement what it will, it is especially important to consider the question of prophylaxis, or how the production of this class of persons can be prevented. They are punished and kept for years in prison, to be finally sent to insane asylums.

Physicians acquainted with insanity should be present at the examination of the inmates of, at least, the large prisons. The judge should also turn his attention more than has previously been the case, to the mental condition of criminals coming before him, especially in young persons, and he need exercise less care in regard to simulation.

The Trustees of the Worcester Lunatic Hospital again express their very strong disapproval of treating the criminal with the ordinary insane. ${ }^{2}$ They say that the first movement toward relieving the overcrowding of the Massachusetts hospitals should be in the direction of separate provision for insane criminals. "That they should be treated upon the same terms as, and allowed to associate with those innocent of criminal act, or thought, is opposed to every sentiment of propriety and justice. . . No criminal, insane or otherwise. should be sent to serve out his sentence to a hospital designed and constructed for the care and cure of innocent and respectable persons, who are so unfortunate as to be sick in mind."

The Trustees think that there is land enough in connection with all the State insane hospitals, upon which buildings might be erected suitable for the treatment of insane criminals. Such buildings could be large enough for two hundred to two hundred and fifty persons, and need not cost more than $\$ 300$ or $\$ 400$ per bed, and they could be supervised and managed by the officers of the general hospital.

At the Maine Insane Hospital, ${ }^{2}$ they " suffer very sensibly" from the presence of twenty-eight insane criminals, and the superintendent thinks it would be wise to erect a separate building for them.

Dr. Eugene Grissom, Superintendent of the North Carolina Insane Asylum, is very emphatic in what he says regarding the association of the criminal with the common insane." "The repeated decisions of the courts sending persons accused of grave crimes to this institution upon a verdict of insanity, are gradually filling our wards with cases that are unfit to be associated with the virtuous insane." In his Report for 1872, he referred to the same evil, and now says that it has been steadily growing in magnitude since that time.

He thinks that the establishment of proper quarters for the criminal insane within the limits of the penitentiary, would tend to diminish the burdens of the courts, and make criminals and their friends less anxious for their acquittal on the ground of insanity.

The Morristown, New Jersey, Asylum also has a number of the criminal insane. ${ }^{2}$ Of these the Superintendent writes :- "While some of them are undoubtedly persons whose crime is the outgrowth of their insanity, and are not more troublesome than other insane persons of the same class, others properly belong to the criminal class, with all their propensities in full vigor, in some cases, intensified by their insanity. . . The ordinary wards of an asylum . . . are not fitted by their construction for the detention of such crafty and determined men. For them there should be provided, either in connection with the prison, or with one of the asylums, a ward, or wards of greater strength and security. . . The need of such provision is also great for such persons as escape conviction from crime on the ground of insanity. . . ."

Dr. Godding, Superintendent of the Government Hospital for the Insane, at Washington, now has fortythree insane criminals under his charge. ${ }^{8}$ The hospital has no special department for this class; therefore, they are, of necessity, placed among the ordinary insane. This is all wrong, Dr. Godding thinks, as insanity is not a crime, and should never be regarded as such. The protection of the community makes it necessary that insane criminals should be securely guarded, but " the professional burglar, overtaken by" insanity, and sent to the hospital, smiles, in his lucid moments, at the window-guards of the dormitory, as if they could ever be thought to represent confinement for him."

\section{CONGRESS OF CRIMINAL ANTHROPOLOGY, ROME, NOVEMBER, 1885.4}

Dr. Motet who presented the report says that all the young students of medicine and law in Italy are deeply influenced by Professor Lombroso, author of the "L'Momo delinquente." The Congress called for discussion of the above subject in the new light thrown upon it by him and others in late years. The question resolves itself into two parts - criminal biology and criminal sociology. The former embraces the study of the criminal in his organic and phychical conditions, and the latter considers how society may best protect itself against him who endangers its security or repose.

Criminal biology. Professor Lombroso laid great weight upon atavism, and Professor Benedikt, of Vienna, said that neurasthenia dominates the whole system of the criminal. He considered insanity and crime such close neighbors, that he proposed to replace the expressions, "culpability" and "punishment" by " harmfulness or danger to society" and "the right of prevention or preservation."

Professor Lombroso exhibited a large number of skulls and passed in review the principal anomalies of development which he said were more frequently met with in criminals than elsewhere.

M. Ferri distinguished two classes of criminals ; the instinctive criminal and the criminal from passion. He said that the insane criminal belonged to the former class. The instinctive criminal is almost always precocious, but the others almost always commit the first crime between the ages of twenty and thirty. From a social point of view, crime is a more profound degeneracy than insanity, since most of the insane are not dangerous, their moral sense having survived the wreck of intelligence.

Professor Sergi considered the question whether there exists a bio-pathological character which predisposes to crime. Criminals often are found to have disease of the nervous system, particularly of the brain. He took for his guide this maxim, "Every sign of morphological degeneracy is also a sign of functional degeneracy."

Prof. Roméo Taverni insisted on the influence of a well-ordered education in producing a well-balanced mind, and also thought that criminals in prisons should 
be carefully classed in order to prevent the pernicious effect of placing those charged with milder offences among hardened criminals.

M. Morselli, whose studies on suicide are well known, sustained with great talent a theory which excited many objections. He believes in the antagonism of homicide to suicide. He concludes that if there sometimes is parallelism between the two, there is usually antagonism. It does not 'seem to us that the statistics of France show this. This question is still a study. (I think this antagonism means that when homicide increases, suicide decreases, and vice versa.)

M. Frigerio said that the born criminal belonged to the epileptic family. The Congress in general did not admit the correctness of this view. The question of simulation led the Congress to express the wish that a special place might be reserved in prisons and asylums where might be kept and observed, every individual suspected of simulating insanity. The Congress also expressed the wish that a museum of criminal anthropology might be formed.

The Congress, without discussion, declared that it was in favor of having measures taken to admit to the penitentiaries professors and students for the study of criminal science.

Professor Lacassague spoke of the expert physician before the courts, and thought it might be well to allow the accused to chose an expert and oppose him to the physician employed by the government.

Dr. Semal, in the preceding Congress at Antwerp, used the following words: "Why hesitate to face this problem, by assuming the hypothesis which gives to crime and insanity a common origin? Especially as the question seems to have arrived at a point where it can be more safely investigated, since we have left the domain of pure theory to enter the more reliable one of clinical experience. From the bosom of every belief, even if pushed to excess, there issue elements of truth destined in future to form a new system of doctrine." We are at the commencement of a great scientific movement and must not mistake its character. Its chief promotors show a vigor and severity in their plans for the protection of society, which have never been displayed before. Nevertheless the individual is not sacrificed, for if he belongs to a certain type, special measures will be adopted for his improvement, but if it is recognized that he can never improve, that he will always be a social danger, he will then be eliminated at once and forever from the society which he menaces.

(To be continued.)

\section{Ulinital $\mathfrak{A g m a r a n d a . ~}$}

\section{A CASE OF FRACTURE OF THE SKULL FOI- LOWED BY ABSCESS.}

BY ATHERTON P. Mason, M.D., of FitchbURa.

THE following case, which occurred in the practice of Dr. George Jewett, of this city, is of more than usual interest as regards its nature, course, and favorable termination. Having watched it closely during the several weeks of my counection with it, and considering it a case well worth reporting, I have prepared the following brief account of it. For the early history $\mathrm{I}$ am indebted to Dr. Jewett, who kindly fur- nished me with notes made by him at the time the patient came to his office.

J. M., laborer, a large, stout Irishman, about fifty years old, came to Dr. Jewett's office on the morning of August 30th, 1885. He had upon the left parietal eminence a contused wound about one and a half inches long, and extending to the bone. He said that the wound had been received the night previous, but was very reticent as to how he came by it. 'The wound was filled with hair which had evidently been cut off by some instrument with a dull edge or moderately sharp corner. After careful cleansing there was found a depression of the skull, scaphoid in shape, one and a half inches long, one-half inch wide, and onequarter inch deep in its widest and deepest portions. The man made no complaint of head or other symptoms, except of tenderness when the wound was touched, and Dr. Jewett observed no symptoms referable to disturbance of the cerebral functions. The wound was dressed antiseptically, the patient was informed of its dangerous character, and absolute rest enjoined; any unfavorable symptom was to be immediately reported.

Nothing further was heard of him until September 5th, when he came again to Dr. Jewett's office ou account of pain in the wound. A bloody, purulent discharge issued from the injured parts. Patient said he had worked steadily during the week past without inconvenience. The wound was dressed as before, and he was told to stay in his house, and on no account to work.

September 7 th a messenger came in haste to Dr. Jewett's office, and said that the man had "had a fit." When seen a short time afterwards, he had a small, hard pulse of 100 , temperature $101^{\circ}$, and slow, stertorous respiration. Was mainly unconscious, but could be partially aroused with difficulty. Nothing particular known of his morning history, except that he was heard to fall heavily while alone in his room. He gradually regained consciousness to a considerable extent, and early in the afternoon of the $7 \mathrm{th}$, Dr. Jewett asked Dr. C. W. Spring and myself to assist him in operating.

After etherizing, which was accomplished with some difficulty, a free crucial incision was made in the scalp, and the site of injury to bone exposed. The depression was found to be quite smooth, except on one side, where the fractured wall was vertical and somewhat fissured. Moderate continuous pressure with an elevator opened a fissure, which furnished a key to the situation. The fractured wall was found to be separated at the diploë. The outer table was easily removed in small fragments, but the inner was much more disturbed, and was removed with difficulty and very cautiously. 'Two sharp fragments were found driven vertically through the dura mater into the substance of the brain. When these were removed, a current of pus welled up from beneath the dura ; considerable arterial hæmorrhage followed, but was soon arrested by the gentle pressure of a carbolized sponge. Marked arterial pulsation was observed in the brain substance. The wound was dressed antiseptically with moderate pressure. Patient came out of the ether well, and was tolerably rational at our departure.

September 8th. Passed a rather wakeful night. Pulse in the morning full, soft, 100 , temperature $99^{\circ}$. Some hæmorrhage from wound; some confusion of ideas. Same condition at evening visit.

September 9th. Pulse 80, temperature normal, 